\title{
The Translation Strategy of Foreign Language from the Perspective of Cross-Cultural Pragmatics
}

\author{
Shanying Fan \\ Hunan Vocational Institute of Safety Technology, Changsha 410151, China.
}

43442365@qq.com

Keywords: Culture; pragmatics; translation.

\begin{abstract}
In this era of information globalization, publicity translation plays an indelible role in carrying forward traditional Chinese culture and enhancing China's international influence. Foreign publicity translation has a direct impact on China's international image in the world. Therefore, effective publicity translation is particularly important. This paper first describes the basic concepts of transcultural translation in cross-cultural pragmatics, explains the relationship between cross-cultural pragmatics and translation, and then enumerates and illustrates some basic principles that need to be followed in the cross-cultural pragmatics. Finally, some commonly used methods and methods of foreign translation are introduced. In the perspective of cross-cultural pragmatics, the strategy of foreign translation is to guide the conduct of foreign language translation with cross cultural pragmatics as the theoretical basis, and to form a standardized and effective foreign translation.
\end{abstract}

\section{The Basic Concepts of Intercultural Pragmatics and External Translation}

\subsection{Basic Concepts of Intercultural Pragmatics.}

Intercultural pragmatics is a new branch of pragmatics. It mainly studies the language and significance of communication between people in different social environment and cultural background, and focuses on the analysis of the environment and laws of language use. The main contents of intercultural pragmatics include three levels: pragmatic level, pragmatic level and pragmatic level [1]. The pragmatic level is not only a shallow analysis of the application of text content and language, but also the analysis of the cultural carrier used. It is the basic level of the study. The cultural implication of the subordinate pragmatic environment is the second level of intercultural pragmatics; the pragmatic subject occupies the dominant position in cross-cultural pragmatics and is in communication. Initiative, regulation and control, with distinctive subject colors, are the third levels of intercultural pragmatics.

\subsection{Basic Concepts of Foreign Translation.}

From the literal aspect of publicity translation, the meaning of publicity translation is very simple, that is, the translation of publicity [2]. The translation of foreign propaganda is a special form of translation. Its core aim is to make the world understand China more deeply, and the translation of foreign language translation has two levels in broad sense and narrow sense. In the broad sense, the translation of foreign language translations covers all kinds of translation activities related to foreign publicity in various fields and departments, and the translation of foreign translation in a narrow sense refers to the relevant translation of the relevant reports of the news media, public signs related to the public institutions, the information of the government and the document public.

\subsection{Intercultural Pragmatics and the Relevance of Foreign Translation.}

According to the basic concepts of cross-cultural pragmatics and translation, the relationship between cross-cultural pragmatics and foreign translation is very close. The translation of transcultural pragmatics is guided by cross-cultural pragmatics, and intercultural pragmatics is embodied in the value of foreign translation. From the perspective of cross-cultural pragmatics and social pragmatics, we will discuss the relationship between cross-cultural pragmatics and publicity translation. 


\subsubsection{Cross Cultural Pragmatic Language Level and Foreign Translation.}

Intercultural pragmatics mainly studies the differences in the expression and understanding of language and behavior among people with different cultural backgrounds. The range and frequency of the use of the same language in different cultural environments are different, and the forms of expression are different.

Equivalent translation at the language level: The target readers of publicity translation are mainly foreigners, overseas Chinese and Hong Kong, Macao and Taiwan compatriots [4]. Therefore, language processing based on cultural factors is particularly important. In 60s, Noida put forward the equivalence theory of translation and distinguished two equal forms of Translation: formal equivalence and dynamic equivalence. In essence, translation is pragmatic and communicative. It is the communication and communication between the two cultures. For a truly successful translation, it is more important to be familiar with the culture than to master the language, because the language has its true meaning and meaning only in its cultural background. With the understanding of the similarities and differences in language background culture, various forms of language can achieve the equivalent effect of publicity translation.

\subsubsection{Cross Cultural Social Pragmatics and Foreign Translation.}

The equivalent translation of intercultural social pragmatic level: Equivalent translation of social pragmatics refers to the equivalent translation of cross language and cross-cultural communication. In the process of translation, it is necessary to achieve the equivalence of social pragmatics. The translator should examine the use of language from different angles, such as the perspective of language, society and culture [5]. A qualified translator should have rich language and cultural experience, have a profound understanding of the source language and target language, have a certain understanding of the social background and culture of the two languages, and also need to take into account the target readers of the translation, thus forming equivalent translation.

\section{Problems in the Translation of Chinese Foreign Propaganda}

With the increasing influence of China in the world, communication with all countries in the world is increasingly frequent, and the scale of the translation of foreign propaganda is rising unprecedentedly. The important speech at home and abroad, the propaganda materials in the world and a sign of the tourist attractions of the state leaders are almost translated into the corresponding foreign language. However, the quality of our foreign translation has not been improved. On the contrary, the translation, the dead translation, the incomprehensible and even ridiculous translation can be seen everywhere.

\section{The Translation Strategy of Foreign Language from the Perspective of Cross-Cultural Pragmatics}

Based on the equivalent translation of language and communication level in cross-cultural pragmatics, the strategies of publicity translation should be discussed in detail to avoid translation failure.

\subsection{Principles of Publicity Translation from the Perspective of Intercultural Pragmatics.}

In order to achieve the final effect of the publicity translation, we must follow the principles of publicity translation from the perspective of cross culture, and guide the process of publicity translation.

\subsubsection{The Different Principles of China and Foreign Countries.}

The principle of distinction between China and foreign countries mainly includes propaganda contents, propaganda measures, publicity objectives and Chinese and foreign language. Because of the differences of values, living habits and cultural backgrounds between China and foreign countries, there are different principles that must be followed in the process of translators' translation in China and foreign countries [6]. To treat this cultural difference with a correct translation attitude is the basis for promoting the effect and level of the translation of the foreign language. The differences 
between Chinese and foreign cultures are mainly reflected in the forms of words, words and grammar, and are greatly influenced by history, geography and traditional culture.

\subsubsection{Outside Principles.}

In the process of the translation of foreign propaganda, we must take into account the different foreign readers and carefully consider the differences between the political, economic and cultural differences between different countries, so as to ensure the effect of the translation of foreign propaganda.

\subsubsection{The Implicit Principle of Euphemism.}

During the translation, the translator must unify the goals and functions of the translation, make the translation meet the needs of the foreign readers, and integrate the cultural acceptance of the target country, so that the translation can promote the cultural tradition of our country better, and enhance the cultural charm and influence of our country.

\subsubsection{The Principle of Defining the Core Status of a Text.}

In the process of the translation of foreign propaganda, it is necessary to make clear the meaning of the text of the external information, and put the words and sentences in the whole text for repeated interpretation, and the true connotation of the interpreter is profound [7]. In the translation of the foreign language, we should focus on exploring the categories of the text and structure of English and Chinese, as well as the thinking meaning of the text. Through the corresponding translation of paragraphs and thinking grammar, it should be translated correctly to improve the effect of the translation of the foreign language, and to reflect the cultural level of our country.

\subsubsection{The Principle of Mutual Understanding.}

Because of the great difference in the economic, historical and cultural development of each country, the values of the state, the way of thinking and the habit of thinking are different. In order to improve the effect of the translation of the foreign language, it is necessary to enhance the communication and communication between the countries, respect the cultural differences between countries, and grasp the needs of the foreign readers. Ask for interest.

\subsubsection{The Principle of National Interests.}

The process of foreign translation is also the process of showing the national image and culture. We should pay full attention to each link of foreign reporting, put the national interests first, and protect the information and cultural security of our country. We should create a good image of the country as the core of publicity translation, effectively protect the national interests and enhance the sense of identity of foreign audiences.

\subsection{Specific Approaches to Publicity Translation from the Perspective of Intercultural Pragmatics.}

The principle of translators in the perspective of cross-cultural pragmatics is to give foreign interpreters guidance in the process of translation, which is the basic guarantee for the effect of foreign translation [8]. On the basis of the principle of translators' translation, it is more effective, more efficient, more accurate and more reasonable to use the professional methods of cross-cultural pragmatics to regulate the grammar, syntax and structure of the translation.

\subsubsection{Domestication and Alienation.}

Domestication and foreignization are two kinds of translation strategies. Foreignization means to respect the language characteristics of foreign culture in translation and adopt the expression of foreign language. It requires translators to tend to the author and destination culture as the destination; domestication is the expression of the native words or sentences expressed in the source language, and the target language is the target of the target reader. Simply speaking, foreignization is the literal translation we often refer to, and domestication means transliteration.

In the process of publicity translation, we should not only translate domestication or foreignization, but only foreignization. The translation of foreign language translation under the multicultural background culture should combine domestication and foreignization effectively. The specific practice is to translate Chinese cultural words and expressions with alienation, highlight Chinese cultural history and cultural background, with the assistance of domestication and translation, and reflect China's respect for foreign languages. 


\subsubsection{Dissipation.}

Translation and culture are inseparable. In terms of publicity and translation, it is difficult to cross cultural barriers. Because it is difficult for the foreign language audience to know or understand the historical information and cultural information attached to the foreign language translation, the information implied in the language of the foreign language translation is difficult to be read and spread, resulting in the dissipation of information [9]. Information dissipation is inevitable in cross-cultural publicity translation, but we can reduce the degree of information dissipation through effective methods. The only way to dissolve the dissipation of translation information caused by cultural differences is to promote the communication and communication of China's foreign culture, gradually put Chinese culture into all parts of the world, and make more and more foreign people understand the Chinese cultural ideas and ways of thinking.

\subsubsection{Reconfiguration.}

In the process of communication, transcultural translation is easy to interpret, value added interpretation and even unread value. By using information reconfiguration strategy, the translation can better transmit the source language information [10]. The specific reconstruction methods include additions, deletion, interpretation, interaction between virtual and reality, and rewriting and reorganization.

\section{Summary}

This paper discusses the basic concepts and basic strategies of translators' translation from the perspective of cross-cultural pragmatics, and introduces the guiding principles of foreign translation and some practical methods of translation. The successful foreign language translation requires the theoretical guidance of cross-cultural pragmatics to make the foreign audience truly understand the content and connotation of the external propaganda, understand the Chinese traditional culture more deeply, enhance the cultural competitiveness of China, and consolidate the position of Chinese culture in the international culture.

\section{Acknowledgements}

This work was supported by the scientific research project of Hunan Vocational Institute of Safety Technology in 2015: A study of transcultural translation based on cross-cultural pragmatics (No.15A04).

\section{References}

[1]. Yuan Zhou. Translation of foreign publicity from the perspective of Modern Rhetoric: Based on the theory of Western persuasion mechanism [J]. Journal of PLA Foreign Languages Institute, 2013, 36 (01): 91-95.

[2]. Zhang Jian. On the "flexible" strategy of publicity translation in the context of Globalization: [J]. foreign language and literature, 2013, 30 (01): 19-27+43+72.

[3]. Hu Xin Gwen, Zhang Jian. The name and reality of publicity translation: an interview with Professor Zhang Jian [J]. Chinese foreign language, 2013, 10 (03): 100-104.

[4]. Jian Yelling. How to improve the readability of publicity translation from punctuation sentences: a case study of "seeking truth" in English translation [J]. Chinese translation, 2013, 34 (04): 110-112.

[5]. Zhu Yehuda. Political consciousness in publicity translation work from "disputed islands" [J]. Chinese translation, 2012, 33 (06): 96-98.

[6]. Hu Fungi, Jian Wen Bo. Publicity Translation: ideologically manipulated rewriting of [J]. Shanghai translation, 2010 (01): 23-28. 
[7]. Hu Fungi. Translation of political texts from the perspective of manipulation theory: Rewriting of political text translation $[\mathrm{J}]$. China Science and technology translation, 2014, 27 (02): 40-42+39.

[8]. Wang Shooing. A study on the strategies of publicity translation from the perspective of intercultural pragmatics [D]. Shanghai International Studies University, 2012.

[9]. Chen Jibe. A strategy of publicity translation based on cross-cultural pragmatics. [J]. Journal of culture, 2017 (04): 187-189.

[10]. Chen Qu. A study on the strategies of publicity translation from the perspective of intercultural pragmatics [J]. Overseas English, 2017 (10): 101+112. 